\title{
REFERENCIAS A LAS ARMAS UTILIZADAS EN LAS LUCHAS NOBILIARIAS GALLEGAS EN EL SIGLO XV
}

\author{
POR \\ GUILLERMO FEDERICO CARLOS FRAGA DIEZ
}

COMO modestísima aportación al tema, recogemos las referencias que figuran en un documento del año 1524, pero que aluden a sucesos ocurridos a finales del siglo xv. Se trata del recuento - efectuado en presencia del notario Antonio del Corral- de las armas existentes en quince fortalezas de la dignidad arzobispal de Santiago.

Como sería muy prolijo enumerar el armamento de cada fortaleza una por una, hacemos una relación general de dichas armas, con alguna ligera anotación que encontramos en otras fuentes de la época referentes a la utilización de tales armas, llamando la atención sobre la coexistencia de las que podríamos llamar tradicionales con las nuevas de fuego.

Las menciones más frecuentes son las que se hacen de las saetas y ballestas. Respecto a las primeras, encontramos unos párrafos cuyo sentido no sabemos penetrar con exactitud, como son los que, al hablar de la catedral de Santiago y de la fortaleza de la Barrera (Barreira), dicen: «... tres arcas llenas de saetas de almazén de Biscaya, mas otras veynte e cuatro dozenas de almazén, las ocho de Altamira e las diez y seis de Biscaya.» Más adelante se habla de la entrega de «un serón de almazén de Biscaya», de la fortaleza de la Plaza, en Santiago: «veynte y quatro dozenas de almazén de Biscaya». Es precisamente esta reiteración a «almazén de Biscaya» lo que nos llama la atención, porque esto se entremezcla con las expresiones «seys dozenas de saetas» (Padrón) y en otras no aparecen las palabras «saeta» y «Biscaya»: «diez y seis dozenas de almazén» (Pontevedra, Lobera, Jallas); «dos manojos de almazén» se hacen constar en el recuento de la fortaleza de Picosacro.

De una herida de saeta murió Bernal Yáñez cuando asaltaba la catedral. La saeta le entró entre la garganta y el hombro, y aunque en el relato que de la visita del barón de Rosmital nos hace Tetzel, que estuvo presente en el acontecimiento, nos dice que el médico que le acompañaba -Fodner- acudió en su ayuda aplicándole un emplasto para sacarle la saeta, el herido falleció a los treinta días, aunque de éstos pasó muy pocos en la cama. Por cierto, que esa caritativa acción iba a producirle al 
médico y a sus acompañantes graves dificultades, ya que incurrieron en excomunión.

Las referencias a las ballestas son numerosas y minuciosas: en la iglesia de Santiago y en la fortaleza de la Barrera había veinte, seis en la torre de la Plaza, ocho en Castro de Montes, seis en Padrón, diez en Pontevedra, seis en Outes, ocho en Lobera, veinte en Picosacro, seis en Grobas, seis en Jallas, seis en el Tapal de Noya, doce en Mexía «y otras de las que se tomaron en la tierra». Sorprende el número de ballestas que se asignan al Picosacro cuando sabemos por otras fuentes que solamente podía albergar diez o doce hombres.

Todas las ballestas citadas estaban acompañadas de sus gafas. Hablando de las sesenta y tres que se encontraban en la iglesia de Saníiago y en la Barrera, se especifica que «se habían tomado en el arzobispado con algunas gafas e poleas e armatostes».

Con una única mención aparece la alabarda (una docena en la iglesia de Santiago y en Barreira), la lanza (se habla de lanzas largas y medias) está innúmeras veces representada en varias fortalezas y todavía son más numerosas las picas (doscientas en Santiago y otras doscientas que se añadieron en la entrega al criado del arzobispo Tabera). Cuando el conde de Camiña creyó que sería atacado por las gentes de Pontevedra, Vasco de Aponte dice: "Puso su gente en ordenanza, delante de la cual para escudarse puso lanzas largas y ballestas y en pos de ellas los caballeros»; y: «En Altamira se presentó con trescientos o cuatrocientos peones encoirazados, medios lanceros e medios ballesteros con sus cascos e con dos trompetas.»

Como armas de fuego se citan escopelas, arcabuces, falconetes, pasalvolantes y espingardones. Las más abundantes son las escopetas: treinta? en la iglesia de Santiago y en Barreira, ocho en Castro de Montes, seis en Padrón, diez en Pontevedra, scis en Outes, seis en Lobera, cinco en Picosacro, seis en Grobas, ocho en Rodeiro y dieciocho en Mexía. De arcabuces sólo hay referencia en la iglesia de Santiago y en Barreira: «... de los cinco existentes los quatro desencavalgados e el uno encavalgado». La referencia al falconete se encuentra en la alusión a «... doce tiros de fuego falconete de yerro con sus cabaletes de palo, los seys con serviclores e los seys sin ellos». Todo ello referido a la iglesia de Santiago y a la fortaleza de la Barrera. De los espingardones sabemos que existían dos en Lobera y otros dos en Mexía. En esta última fortaleza había también dos pasavolantes.

Con una espingarda ocasionó un escudero llamado Alonso Ramírez, que era portugués, la muerte de Francisco y Lope de Aballe en el cerco de Fornelos: «... armó una espingarda y tiró a uno de los capitanes por enmedio de los pechos o de la garganta y pasándole todas las armas dio 
con él muerto en tierra. El otro capitán alzó el capacete, y queriendo ver cómo había caído, tan presto ya el matador tenía armada o cargada y otra tiróle o disparóle y dióle por la boca o por un ojo. Aún me dijeron - añade Vasco de Aponte- que ambas partes lo ferira, porque cuentan que estas espingardas a veces tiran con dos plomos o balas.»

De la existencia de trabucos tenemos noticias en los sitios de las fortalezas de Altamira y Mexía, recibiendo también el mismo nombre una máquina de contrapeso.

Con relación a estas armas de fuego, hay numerosas referencias a cantidades de plomo para hacer pellas, moldes, atacadores, frascos y cebaderos y pólvora: «... tres cueros llenos de pólvora - que serán quintal y medio- en la fortaleza de la iglesia, catorce libras y media en Castro de Montes, dos libras en Outes, etc.»

Se empleaban proyectiles de piedra: sabemos por Diego de Valera que en el año 1458 el conde de Trastamara intentó dominar la fortaleza arzobispal de la Rocha Fuerte disparando en los seis meses que duró el frustrado cerco por medio de «tres yngenios y otros pertrechos, mill e quinientas piedras de yngenio». También se habla reperidamente de «dozenas de tiros».

$Y$ por fin, y para terminar, se hacen abundantes referencias a coseletes —unos enteros y otros a los que les faltaban piezas-, celadas, brazales, paveses, rodelas, escudos, gorjales de malla «e cierta malla vieja que avía seydo de un sayo e una cota vieja de malla». 